\title{
Nails and Rivets: Pre-Nineteenth Century
}

\author{
Mark A. Hineman* and Frederick E. Schmidt, Jr. * \\ * Engineering Systems Inc., 3851 Exchange Avenue, Aurora, IL. 60504
}

Fastener technology in the pre-nineteenth century has been given very little attention from a metallurgical perspective. At best, we can infer from the American colonial records that hand fashioned, hammer forged and perhaps as manufactured nails and rivets were produced by blacksmith type artisans. The two examples that were examined in this metallographic investigation were found in West Chester County, Pennsylvania. The rivet appears to be swaged and cut from a preformed rod shape. It is one of many associated with the Phoenix Iron Column structures (1850 to 1895). The nail was obtained from a revolutionary war era barn site. It is concluded that the composition and microstructure of the as-installed fasteners were never melted as in a cast process. Instead the macro \& micro structures are consistent with being hammered into place as indicated by the metal flow lines. The function of the fasteners in both instances was a mechanical wedging, to achieve the required retention forces by interference fit. Specifically, no heating was apparent in the hammer heading installation of the rivets.

Background: In a previous study ${ }^{[1]}$ of Phoenix Iron Works, circa 1863, bridge and column structures contained high phosphorous nominal averaged $(0.36 \%)$ and local inclusion concentrations $(4.0 \%)$ were found. This investigation was conducted to determine if these contemporaneous fasteners were made from the same metallurgical process for both rivets and nails.

Micro Structural Detail: Photo micrograph Figure \#1 - exhibits cold swaged of the rivet, with large well dispersed multiphase inclusions containing Phosphorus rich phases. The substructure contains dispersed oxides and silicates that were isolated. These are very similar in appearance to the microstructure of previously examined Phoenix Iron. Figure \#2 - a mount, contains both a curved longitudinal transverse section and a parallel section of macrostructure to the rolling direction indicating a plate forming process was used. Figure \#3 indicates an interference fit, was caused by upsetting the rivet by a cold hammering process. We could not find any evidence of a metallurgical bond. Therefore, with no fusion evident at the joint we conclude a mechanical interlocking was intended. The material in the gap was analyzed to be like Fe O, mill scale. Figure \#4, clearly shows a ferrite type banding microstructure consistent with both a higher percentage of carbon and ferrite banding. Mechanical fibering contributes directional strength in the long direction of the cold formed nails. The tapered, wedge shape of these early nails combined with a rather rough hewn surface finish was intended to promote friction and engagement.

Summary: Energy Dispersive Spectroscopy (EDS) spectra were averaged using the SEM at $20 \mathrm{KVa}$. It was found that the rivet did contain significant levels of phosphorous and most likely was made from a material derived from Phoenix Iron type of processing. Regarding, the rivet sample, the carbon content was much higher and more varied from 0.13 to $0.19 \%$. The nail evaluated had a carbon level $0.32 \%$, with $0.51 \%$ manganese as the only other alloy element. Since the nail contained a lamellar structure and exhibited banding and no phosphorous, it is concluded that it was not derived from Phoenix Iron or similar metallurgical processing.

[1] M. A. Hineman, F. E. Schmidt, Jr., et al, Microsc. Microanal. 13 (Suppl 2) pp. 116/117, (2007) 


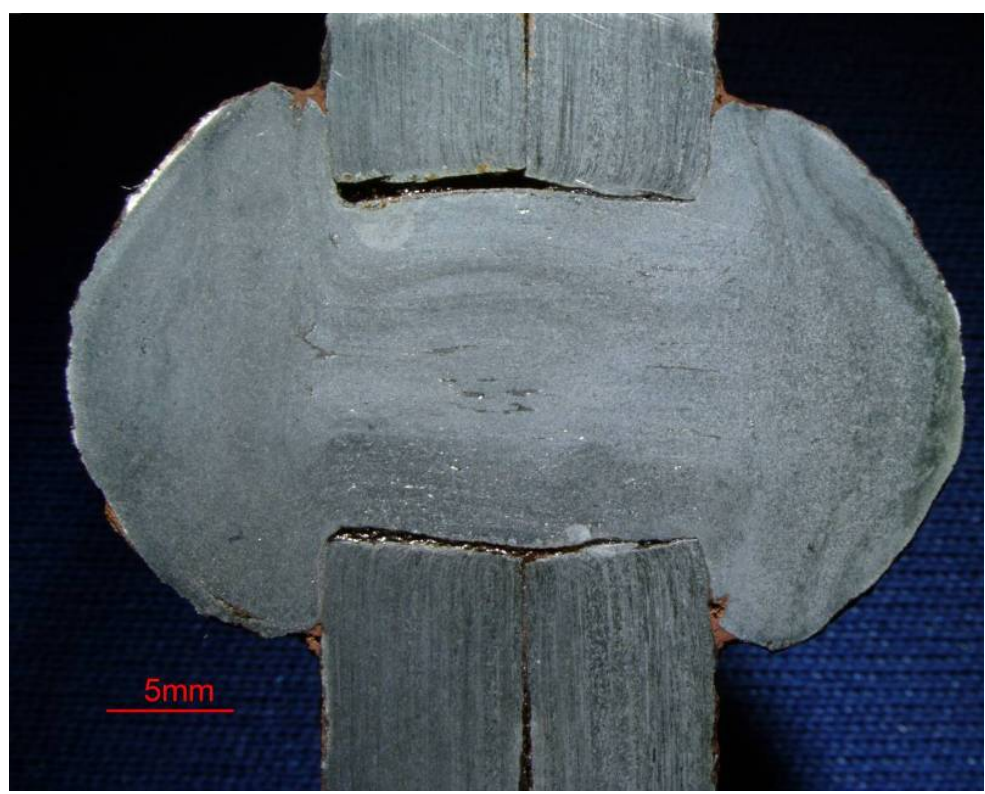

Figure. 1: Macroscopic section through rivet.

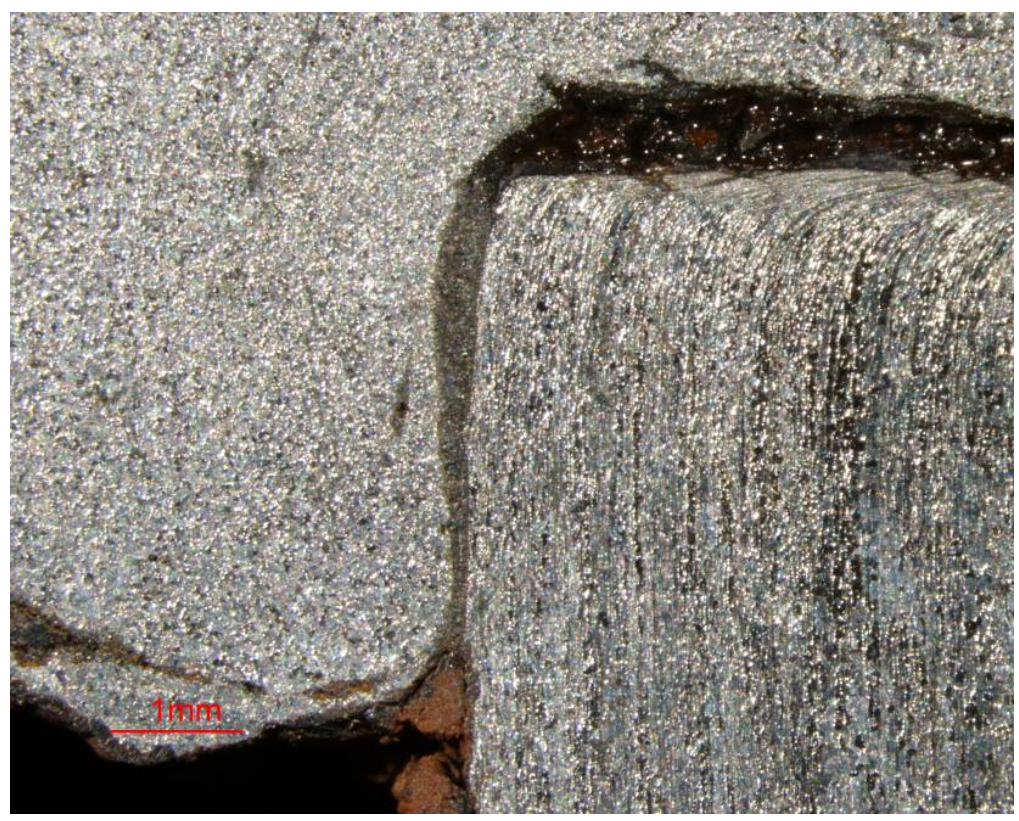

Figure. 3: Material between rivet and column.

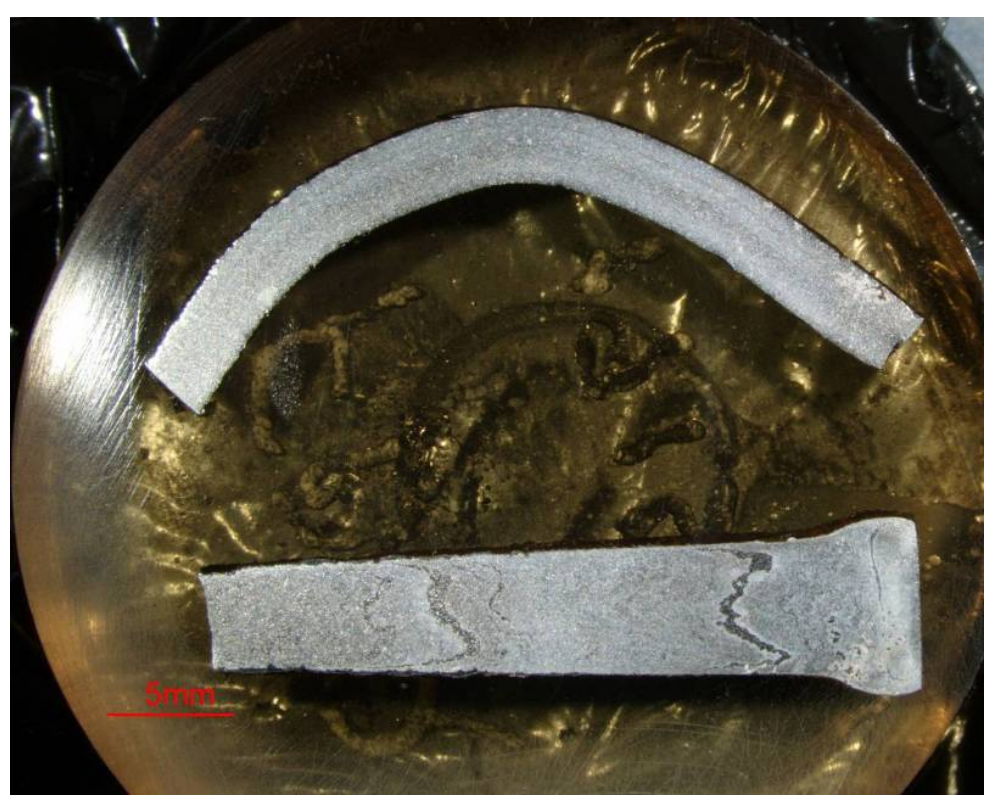

Figure. 2: Macroscopic image of the nail sections.

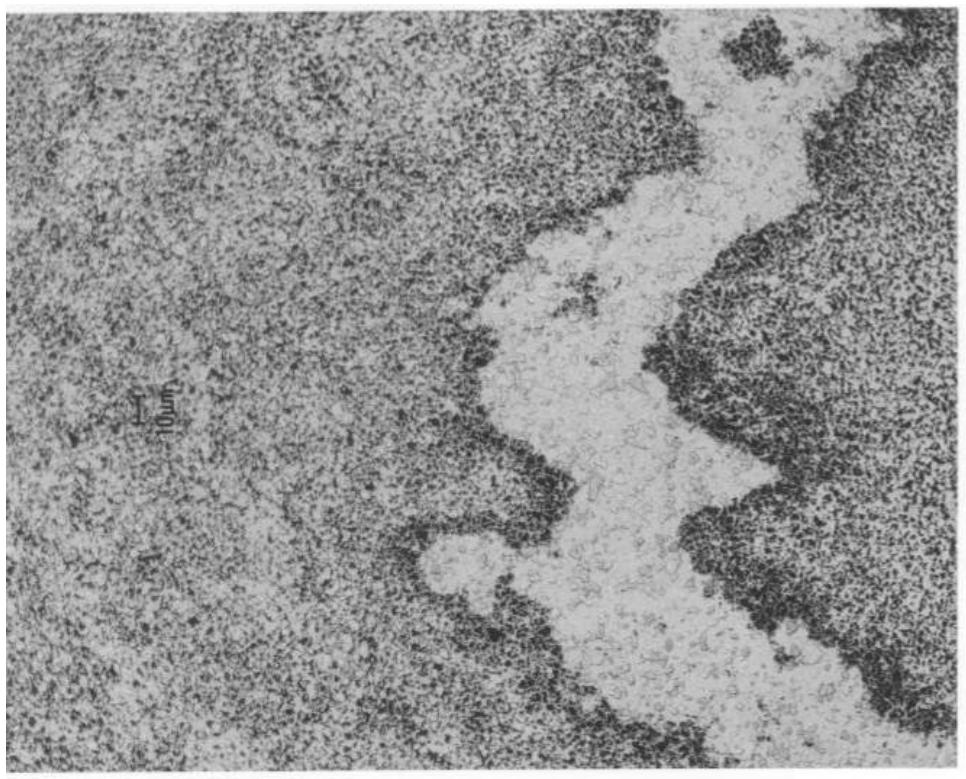

Figure 4: Microstructure of nail section (5\% nital) 